\title{
Lung protective mechanical ventilation strategies in cardiothoracic critical care: a retrospective
} study

\author{
Vasileios Zochios ${ }^{1-3}$ \\ Matthew Hague ${ }^{3,4}$ \\ Kimberly Giraud ${ }^{5}$ \\ Nicola Jones ${ }^{3}$
}

'Department of Intensive Care Medicine, Queen Elizabeth Hospital Birmingham, University Hospitals Birmingham NHS Foundation Trust, ${ }^{2}$ Institute of Inflammation and Ageing, College of Medical and Dental Sciences, University of Birmingham, ${ }^{3}$ Department of Anesthesia and Intensive Care Medicine, Papworth Hospital NHS Foundation Trust, Papworth Everard, Cambridge, ${ }^{4}$ Department of Medicine, Colchester Hospital University NHS Foundation Trust, Colchester General Hospital, Colchester, ${ }^{5}$ Research and Development Department, Papworth Hospital NHS Foundation Trust, Papworth Everard, Cambridge, UK
Correspondence: Vasileios Zochios Department of Intensive Care Medicine, Queen Elizabeth Hospital Birmingham, University Hospitals Birmingham NHS Foundation Trust, Birmingham, BI5 2GW, UK

Tel +44 I I I 6272000

Email vasileioszochios@doctors.org.uk
This article was published in the following Dove Press journal:

International Journal of General Medicine

II November 2016

Number of times this article has been viewed

\begin{abstract}
A body of evidence supports the use of low tidal volumes in ventilated patients without lung pathology to slow progress to acute respiratory distress syndrome (ARDS) due to ventilator associated lung injury. We undertook a retrospective chart review and tested the hypothesis that tidal volume is a predictor of mortality in cardiothoracic (medical and surgical) critical care patients receiving invasive mechanical ventilation. Independent predictors of mortality in our study included: type of surgery, albumin, $\mathrm{H}^{+}$, bilirubin, and fluid balance. In particular, it is important to note that cardiac, thoracic, and transplant surgical patients were associated with lower mortality. However, our study did not sample equally from The Berlin Definition of ARDS severity categories (mild, moderate, and severe hypoxemia). Although our study was not adequately powered to detect a difference in mortality between these groups, it will inform the development of a large prospective cohort study exploring the role of low tidal volume ventilation in cardiothoracic critically ill patients.
\end{abstract}

Keywords: lung protective ventilation, cardiothoracic critical care, acute respiratory distress syndrome, invasive mechanical ventilation

\section{Introduction}

Positive pressure mechanical ventilation (MV) can lead to ventilator associated lung injury (VALI) due to cyclic alveolar atelectasis and strain. Risk factors for VALI in patients without acute respiratory distress syndrome (ARDS) include high tidal volume $\left(\mathrm{V}_{\mathrm{t}}>6 \mathrm{~mL} / \mathrm{kg}\right.$ predicted body weight [PBW]), acidemia, blood product transfusion, and restrictive lung disease. ${ }^{1}$ A randomized controlled trial (RCT) of low tidal volume ventilation in patients with mild ARDS (the term acute lung injury has been replaced with mild ARDS: $26.6 \mathrm{kPa}<$ partial pressure of arterial oxygen $\left(\mathrm{PaO}_{2}\right) /$ fraction of inspired oxygen $\left.\left(\mathrm{F}_{\mathrm{i}} \mathrm{O}_{2}\right) \leq 40 \mathrm{kPa}\right),{ }^{2-4}$ carried out by the ARDS Network, demonstrated an $8.8 \%$ absolute reduction in short term mortality. ${ }^{3-5}$

There is a body of evidence supporting the use of low tidal volume $\left(\mathrm{V}_{\mathrm{t}} 6-8 \mathrm{~mL} / \mathrm{kg}\right.$ PBW) in slowing progression to ARDS in patients with normal lungs. ${ }^{4}$ Gajic et al demonstrated that $24 \%$ of intensive care unit (ICU) patients with noninjured lungs, who received MV for 2 days or longer, developed ARDS within the first 5 days of MV. A multivariate analysis revealed an increased risk of developing ARDS with the use of volumes $>6 \mathrm{~mL} / \mathrm{kg}$ PBW (odds ratio [OR] 1.3 for every $1 \mathrm{~mL}>6 \mathrm{~mL} / \mathrm{kg}$ PBW, $P<0.001)$. A large database analysis of over 3,000 mechanically ventilated ICU patients without ARDS showed that ARDS developed in $6.2 \%$ of patients after 48 hours of MV. A multivariate analysis revealed that the use of a $\mathrm{V}_{\mathrm{t}}>700 \mathrm{~mL}$ was associated with an OR of 2.66 for the development of ARDS $(P<0.001))^{1,4,5}$ submit your manuscript Dovepress if in $>$ 
The use of lung damaging ventilation strategies (large $\mathrm{V}_{\mathrm{t}} \mathrm{s}$ and high plateau pressures) in patients who develop subclinical lung injury during surgery, which involves large pulmonary resection or cardiopulmonary bypass (CPB), can contribute to ARDS in noninjured lungs. ${ }^{6,7}$

Based on the current evidence and understanding of MV and ARDS, it would seem reasonable to use lung protective ventilation $\left(\mathrm{V}_{\mathrm{t}} 6-8 \mathrm{~mL} / \mathrm{kg}\right.$ PBW, low plateau pressures and positive end-expiratory pressure [PEEP]) in all patients, whether they are at risk of ARDS or not. ${ }^{1-7}$ However, use of least damaging ventilation settings is not always feasible. Patients with airway obstruction (chronic obstructive airway disease, asthma) who may have increased intrinsic PEEP or patients with interstitial lung disease who have restrictive lung disease and poor lung compliance may require higher plateau pressures to ensure adequate gas exchange.

Patients undergoing cardiac surgery are particularly sensitive to lung damage due to prolonged MV, multiple comorbidities, and pro-inflammatory cofactors such as $\mathrm{CPB}$, transfusions, and ischemia/reperfusion. ${ }^{8,9}$

\section{Aims and objectives}

The aim of our study was to test the hypothesis that tidal volume is a predictor of mortality in the cohort of cardiothoracic critically ill patients.

Additional aims of this project were 1) to identify the commonly used ventilatory modes and parameters in our cardiothoracic ICU (postoperative and nonsurgical patients), 2) to identify whether certain components of lung protective ventilation care bundles are followed by our institution's cardiac intensivists at the onset of MV, 3) to help develop a ventilatory guideline within our cardiac ICU and cardiac recovery unit and integrate a ventilator bundle in checklist format in our electronic clinical information system, and 4) to organize teaching sessions on lung protective strategies for all ICU medical, nursing, and allied health professionals.

\section{Methodology}

We performed a retrospective database analysis of patients $>18$ years admitted to tertiary center high volume cardiothoracic ICU between 01/01/2015 and 15/08/2015 requiring MV for $\geq 48$ hours ( $\mathrm{n}=189$ ).

Exclusions were made for:

- Patients who did not require invasive MV.

- Patients who required strict $\mathrm{PaCO}_{2}$ control (eg, in post cardiac arrest syndrome goal directed ventilatory strategy).
- Patients for whom ICU electronic daily charts are unavailable.

Predictor variables in the first 24 hours extracted from clinical information system included sequential organ failure assessment (SOFA) score at the onset of MV, ventilator mode, $\mathrm{V}_{\mathrm{t}}$, respiratory rate, $\mathrm{PEEP}, \mathrm{FiO}_{2}, \mathrm{pH}, \mathrm{PaO}_{2}$, arterial partial pressure of carbon dioxide $\left(\mathrm{PaCO}_{2}\right)$, peak airway pressure, compliance, $\mathrm{PaO}_{2} / \mathrm{FiO}_{2}$ ratio, albumin, bilirubin, fluid balance, $\left[\mathrm{H}^{+}\right]$, and types of surgery (cardiac/thoracic, transplant, and nonsurgical). Outcome variables included ICU and 90-day mortality.

This project has been reviewed and approved by the Research and Development Unit of Papworth Hospital NHS Foundation Trust - it has no material ethical issues. The Research and Development Unit on behalf of Papworth Hospital NHS Foundation Trust has reviewed this project and did not require written informed consent be obtained from the participants, as this was a retrospective study and service evaluation, and all data was anonymous.

\section{Statistical analysis}

Statistical software Stata/SE 13.1 for Mac was used (StataCorp, 2013, Stata Statistical Software: Release 13, StataCorp LP, College Station, TX, USA). Univariate logistic/ linear regressions identified predictor variables to include in multivariate regressions (reduce risk of overfitting) at $P<0.20$. Multiple logistic/linear regressions, adjusting for covariates, identified independent significant predictors for outcome variables.

\section{Results}

Overall, 129 patients were identified according to the inclusion criteria. Twenty-nine percent were female and $71 \%$ were male. Sixty-four percent were admitted to ICU following cardiac/thoracic or transplant surgery, 25\% for nonsurgical reasons (cardiothoracic medical pathologies) and $11 \%$ were patients who were readmitted in the postoperative period. Of all patients, $7 \%$ were admitted following coronary artery bypass grafting surgery, $9 \%$ following valve replacement/ repair, $16 \%$ following combined valve and other procedure, $14 \%$ following heart and/or lung transplant, and $0.8 \%$ following video-assisted thoracoscopic surgery. All patients included in the study were mechanically ventilated on Siemens Servo-I ventilators. Summary statistics for initial choice of ventilator mode are demonstrated in Table 1. Mean SOFA score at onset of MV was $13 \pm 2.5$ (standard deviation).

Predictor variables (in the first 24 hours) retained for inclusion in multiple regression model: gender, type of 
Table I Summary statistics of initial ventilator mode for each patient in sample

\begin{tabular}{ll}
\hline Ventilator mode & $\begin{array}{l}\text { Patients } \\
(\mathbf{N}=1 \mathbf{2 9}), \mathbf{n}(\%)\end{array}$ \\
\hline SIMV (PRVC) + pressure support & $57(44)$ \\
Volume control & $36(28)$ \\
SIMV (pressure control) + pressure support & $1 \mathrm{I}(9)$ \\
Pressure control & $1 \mathrm{I}(9)$ \\
PRVC & $10(8)$ \\
Pressure support/CPAP & $2(2)$ \\
SIMV (volume control) + pressure support & $\mathrm{I}(\mathrm{I})$ \\
CMV (volume control) & $\mathrm{I}(\mathrm{I})$ \\
\hline
\end{tabular}

Abbreviations: $\mathrm{CMV}$, continuous mandatory ventilation; CPAP, continuous positive airway pressure; PRVC, pressure regulated volume control; SIMV, synchronized intermittent mandatory ventilation.

surgery, admission type, $\mathrm{V}_{\mathrm{t}}, \mathrm{FiO}_{2}, \mathrm{PaO}_{2}, \mathrm{PaO}_{2} / \mathrm{FiO}_{2}$ ratio, $\mathrm{PaCO}_{2}$, albumin, platelet count, $\mathrm{H}^{+}$, total bilirubin, and fluid balance. When controlling for covariates, $\mathrm{V}_{\mathrm{t}}$ and other ventilator variables did not independently predict mortality in our model, despite best evidence suggesting that they should (Tables 2-4).

\section{Discussion}

When controlling for covariates, $\mathrm{V}_{\mathrm{t}}$ and other ventilator variables did not independently predict mortality in our model, despite best evidence suggesting that they should.

Table 2 Ninety-day mortality

\begin{tabular}{|c|c|c|}
\hline 90-day mortality & $\begin{array}{l}\text { Regression } \\
\text { coefficient }(95 \% \mathrm{Cl})\end{array}$ & $P$-value \\
\hline Mean $\mathrm{PaO}_{2} / \mathrm{FiO}_{2}$ ratio & $\begin{array}{l}0.0025812 \\
(-0.005,0.010)\end{array}$ & 0.520 \\
\hline Surgery type & $\begin{array}{l}-0.803942 \mid \\
(-1.375,-0.233)\end{array}$ & 0.006 \\
\hline Mean albumin $(g / L)$ & $\begin{array}{l}-0.2022619 \\
(-0.320,-0.085)\end{array}$ & 0.001 \\
\hline Mean $\mathrm{H}^{+}$ & $\begin{array}{l}0.0744572 \\
(0.002,0.146)\end{array}$ & 0.044 \\
\hline Mean bilirubin & $\begin{array}{l}0.0219693 \\
(0.001,0.043)\end{array}$ & 0.039 \\
\hline Mean fluid balance & $\begin{array}{l}-0.0007785 \\
(-0.00151,-0.0000376)\end{array}$ & 0.039 \\
\hline Mean platelet count & $\begin{array}{l}0.0010963 \\
(-0.002,0.005)\end{array}$ & 0.579 \\
\hline Mean $\mathrm{V}_{\mathrm{t}}(\mathrm{mL})$ & $\begin{array}{l}0.0040282 \\
(-0.002,0.010)\end{array}$ & 0.214 \\
\hline Mean $\mathrm{PaO}_{2}(\mathrm{kPa})$ & $\begin{array}{l}0.0822255 \\
(-0.094,0.259)\end{array}$ & $0.36 \mathrm{I}$ \\
\hline Mean $\mathrm{PaCO}_{2}(\mathrm{kPa})$ & $\begin{array}{l}-0.4574553 \\
(-1.186,0.27 I)\end{array}$ & 0.218 \\
\hline Gender & $\begin{array}{l}-0.4365685 \\
(-1.546,0.673)\end{array}$ & $0.44 I$ \\
\hline
\end{tabular}

Abbreviations: $\mathrm{Cl}$, confidence interval; $\mathrm{PaO}_{2}$, partial pressure of arterial oxygen; $\mathrm{FiO}_{2}$, fraction of inspired oxygen; $\mathrm{PaCO}_{2}$, arterial partial pressure of carbon dioxide.
Table 3 CCA mortality

\begin{tabular}{lll}
\hline CCA mortality & $\begin{array}{l}\text { Regression coefficient } \\
(\mathbf{9 5 \%} \mathbf{~ C l})\end{array}$ & P-value \\
\hline Mean $\mathrm{PaO}_{2} / \mathrm{FiO}_{2}$ ratio & $-0.0012962(-0.012,0.009)$ & 0.808 \\
Surgery type & $-2.06707(-3.15,-0.984)$ & 0.000 \\
Mean albumin $(\mathrm{g} / \mathrm{L})$ & $-0.188557(-0.324,-0.053)$ & 0.006 \\
Mean $\mathrm{H}^{+}$ & $0.076753 \mathrm{I}(-0.009,0.162)$ & 0.078 \\
Mean bilirubin & $0.023340 \mathrm{I}(-0.002,0.048)$ & 0.067 \\
Mean fluid & $-0.0000732(-0.00 \mathrm{I}, 0.0009)$ & 0.877 \\
balance & & \\
Mean platelet count & $-0.0023714(-0.008,0.003)$ & 0.378 \\
Mean $\mathrm{V}_{\mathrm{t}}(\mathrm{mL})$ & $0.0026183(-0.005,0.01 \mathrm{I})$ & $0.52 \mathrm{I}$ \\
Mean $\mathrm{PaO}_{2}(\mathrm{kPa})$ & $0.093860 \mathrm{I}(-0.125,0.3 \mathrm{I})$ & 0.400 \\
Mean $\mathrm{PaCO}_{2}(\mathrm{kPa})$ & $-0.0468 \mathrm{I} 57(-0.930,0.836)$ & 0.917 \\
Gender & $0.0823749(-\mathrm{I} .263, \mathrm{I} .428)$ & 0.904 \\
\hline
\end{tabular}

Abbreviations: $\mathrm{Cl}$, confidence interval; $\mathrm{CCA}$, critical care area; $\mathrm{PaO}_{2}$, partial pressure of arterial oxygen; $\mathrm{FiO}_{2}$, fraction of inspired oxygen; $\mathrm{PaCO}_{2}$, arterial partial pressure of carbon dioxide.

Table 4 Summary statistics of ARDS severity in sample

\begin{tabular}{|c|c|c|c|c|c|}
\hline \multirow{2}{*}{$\begin{array}{l}\text { ARDS } \\
\text { severity }\end{array}$} & \multicolumn{2}{|c|}{ ICU mortality } & \multicolumn{2}{|c|}{ 90-day mortality } & \multirow[t]{2}{*}{ Total } \\
\hline & Yes (\%) & No (\%) & Yes (\%) & No (\%) & \\
\hline None & $23 / 99(23)$ & $12 / 30(40)$ & $18 / 83(22)$ & $17 / 46(37)$ & $35 / 129(27)$ \\
\hline Mild & $44 / 99$ (44) & $8 / 30(27)$ & $36 / 83(43)$ & $16 / 46(35)$ & $52 / 129(40)$ \\
\hline Moderate & $27 / 99$ (27) & $10 / 30(33)$ & $24 / 83(29)$ & $13 / 46(28)$ & $37 / 129(29)$ \\
\hline Severe & $5 / 99(5)$ & $0 / 30(0)$ & $5 / 83(6)$ & $0 / 46(0)$ & $5 / 129(4)$ \\
\hline
\end{tabular}

Abbreviations: ARDS, acute respiratory distress syndrome; ICU, intensive care unit.

Independent predictors of mortality in our study included: type of surgery, albumin, $\mathrm{H}^{+}$, bilirubin, and fluid balance. In particular, it is important to note that cardiac, thoracic, and transplant surgical patients were associated with lower mortality. This could reflect the expertise of our institution as a cardiothoracic center in ensuring the best outcomes for these patients. The Berlin Definition of ARDS severity ${ }^{10}$ categorizes patients on their degree of hypoxemia (mild, moderate, and severe based on $\mathrm{PaO}_{2}: \mathrm{FiO}_{2}$ ratio) which should predict mortality. However as demonstrated in Table 3, we did not sample equally from each of these groups. As a result, our study was not adequately powered to detect a difference in mortality between these groups and therefore our results are not definitive. Further study of this sample would add the required power or use subgroup analyses to determine all factors contributing to death.

\section{Acknowledgment}

An abstract of this paper was presented as a poster at the Critical Care Canada Forum on 2nd November 2016 at Sheraton Centre Toronto Hotel, Toronto, ON, Canada.

\section{Disclosure}

The authors report no conflicts of interest in this work. 


\section{References}

1. Neto AS, Cardoso SO, Manetta JA, et al. Association between use of lung-protective ventilation with lower tidal volumes and clinical outcomes among patients without acute respiratory distress syndrome: a meta-analysis. JAMA. 2012;308(16):1651-1659.

2. Gajic O, Dara SI, Mendez JL, et al. Ventilator-associated lung injury in patients without acute lung injury at the onset of mechanical ventilation. Crit Care Med. 2004;32(9):1817.

3. Brower RG, Matthay MA, Morris A, Schoenfeld D, Thompson BT, Wheeler A. Ventilation with lower tidal volumes as compared with traditional tidal volumes for acute lung injury and the acute respiratory distress syndrome. The acute respiratory distress syndrome network. $N$ Engl J Med. 2000;342(18):1301-1308.

4. Gajic O, Frutos-Vivar F, Esteban A, Hubmayr RD, Anzueto A.Ventilator settings as a risk factor for acute respiratory distress syndrome in mechanically ventilated patients. Intensive Care Med. 2005;31(7):922-926.

5. Petrucci N, De Feo C. Lung protective ventilation strategy for the acute respiratory distress syndrome. Cochrane Database Syst Rev. 2013;(2):CD003844.
6. Putensen C, Theuerkauf N, Zinserling J, Wrigge H, Pelosi P. Metaanalysis: ventilation strategies and outcomes of the acute respiratory distress syndrome and acute lung injury. Ann Intern Med. 2009;151(8): 566-576.

7. Zupancich E, Paparella D, Turani F, Munch C, Rossi A, Massaccesi S, Ranieri VM. Mechanical ventilation affects inflammatory mediators in patients undergoing cardiopulmonary bypass for cardiac surgery: a randomized clinical trial. J Thorac Cardiovasc Surg. 2005;130(2): 378-383.

8. Lipes J, Bojmehrani A, Lellouche F. Low tidal volume ventilation in patients without acute respiratory distress syndrome: a paradigm shift in mechanical ventilation. Crit Care Res Pract. 2012;2012:41686.

9. Schreiber JU, Lancé MD, de Korte M, Artmann T, Aleksic I, Kranke P. The effect of different lung-protective strategies in patients during cardiopulmonary bypass: a meta-analysis and semiquantitative review of randomized trials. $J$ Cardiothorac Vasc Anesth. 2012;26(3): 448-454.

10. Ranieri VM, Rubenfeld GD, Thompson BT, et al; The ARDS Definition Task Force. Acute respiratory distress syndrome: the Berlin definition. JAMA. 2012;307(23):2526-2533.
International Journal of General Medicine

\section{Publish your work in this journal}

The International Journal of General Medicine is an international, peer-reviewed open-access journal that focuses on general and internal medicine, pathogenesis, epidemiology, diagnosis, monitoring and treatment protocols. The journal is characterized by the rapid reporting of reviews, original research and clinical studies across all disease areas.

\section{Dovepress}

The manuscript management system is completely online and includes a very quick and fair peer-review system, which is all easy to use. Visit http://www.dovepress.com/testimonials.php to read real quotes from published authors

Submit your manuscript here: https://www.dovepress.com/international-journal-of-general-medicine-journal 